NASA Technical Memorandum 89843

\title{
The Acousto-Ultrasonic Approach
}

\author{
(NASA-TH-89843) TEE ACCUSTC-CIIEASONIC
AEERCACH (NASA) $30 \mathrm{p}$
}

N87-20562

Unclas

45389

\section{Alex Vary \\ Lewis Research Center \\ Cleveland, Ohio}

Prepared for the

Acousto-Ultrasonics: Theory and Application cosponsored by NASA and the American Society for Nondestructive Testing Blacksburg, Virginia, July 12-15, 1987 
THE ACOUSTO-ULTRASONIC APPROACH

\author{
Alex Vary \\ National Aeronautics and Space Administration \\ Lewis Research Center \\ cleveland, Ohio 44135
}

\title{
SUMMARY
}

This paper reviews the nature and underlying rationale of the acousto-ultrasonic approach, suggests needed advanced signal analysis and evaluation methods, and discusses application potentials. The term acousto-ultrasonics denotes an NDE technique that combines some aspects of acoustic emission methodology with ultrasonic simulation of stress waves. The acousto-ultrasonic approach uses analysis of simulated stress waves for detecting and mapping variations of mechanical properties. Unlike most NDE, acousto-ultrasonics is less concerned with flaw detection than with the assessment of the collective effects of various flaws and material anomalies. Acousto-ultrasonics has been applied chiefly to laminated and filament-wound fiber reinforced composites. It has been used to assess the significant strength and toughness reducing effects that can be wrought by combinations of essentially minor flaws and diffuse flaw populations. Acousto-ultrasonics assesses integrated defect states and the resultant variations in properties such as tensile, shear, and flexural strengths and fracture resistance. Matrix cure state, porosity, fiber orientation, fiber volume fraction, fiber-matrix bonding, and interlaminar bond quality are factors that underline acousto-ultrasonic evaluations.

\section{INTRODUCTION}

Conventional NDE. - The main purpose of nondestructive evaluation (NDE) is to provide a basis for determining whether a structure will perform reliably when placed in service. This is usually done with conventional flaw detection 
techniques and it depends on defining which flaws are harmful. Obviously, it is unrealistic to discard a part simply because it contains minor flaws or anomalies that normally arise during fabrication. Certainly, some flaws are likely to be more harmful than others because of their size, location, and proximity to each other. But, in some materials (e.8., fiber reinforced composites) the harmful effects of certain types of flaws cannot always be determined unambiguously.

Although composites can have broken fibers, delaminations, local porosity, resin rich areas, etc., the overall effect may be benign. The combined effect of these defects is often difficult to assess analytically. More theoretically valid analysis models are needed to incorporate the complex fracture process that occur in composites. ${ }^{1}$ on the other hand, a composite structure may be free of readily detectable flaws but still exhibit low strength and be unsuitable for use. Low composite strength may be due to poor bonding between plies or between the fibers and matrix.

Mechanical Property Assessment. - The preceding observations suggest a need for NDE methods that can assess variations in mechanical properties rather than merely detect minor flaws whose relevance is questionable. These methods should at least quantify relative strength and fracture resistance by measuring the combined effect of all deficiencies due to subcritical flaw populations and microstructural anomalies in a volume of material. Then, fracture analysis and analytical life prediction methods would be supplemented by NDE approaches that verify properties that contribute to structural integrity and reliability. ${ }^{2}$

Acousto-ultrasonics. - The acousto-ultrasonic approach addresses the above-mentioned requirements. ${ }^{3}$ It complements other NDE approaches to materials characterization and of fers advantages that make it the preferred one to use in some cases. Accordingly, the purpose of this paper is to 
describe the acousto-ultrasonic approach, its genesis, rationale, signal analysis methods, and applications.

\section{BACKGROUND}

Terminology. - The term acousto-ultrasonics was coined to express the close relation with acoustic emission. "Acousto-ultrasonics" may be taken as a contraction of "acoustic emission simulation with ultrasonic sources." Acousto-ultrasonic waves like acoustic emissions are generally ultrasonic in nature. The acoustic emission method depends on loading to excite spontaneous stress waves such as those accompanying plastic deformation and crack growth. 5 Acousto-ultrasonics differs mainly in that the ultrasonic waves are benign and are generated externally by a pulsed source (usually a piezotransducer). 6

objective. - The objective in acousto-ultrasonics is to simulate stress waves that resemble acoustic emission waves but without disrupting the material. 7 Once launched inside the material sample, the waves are modified by stochastic processes like those that affect spontaneous acoustic emissions from internal sources during stressing, deformation, etc. Horeover, acousto-ultrasonic waves are launched periodically at predetermined times and with predetermined repetition rates.

In contrast to acoustic emission practice, the idea in acousto-ultrasonics is to keep the nature and location of the source of ultrasonic radiation known and fixed. Then, the inverse problem is not concerned with source location and characterization but with characterization of the material medium between the source and receiver. 8

Alternative Approaches. - Materials characterization can, of course, be accomplished by other ultrasonic methods, 9 for example, by pulse-echo ultrasonic measurements of velocity and attenuation. These measurements can usually be correlated with variations in microstructure (e.8., grain size, porosity), elastic constants, strength, toughness, etc. Pulse-echo ultrasonics 
is based on knowing the wave propagation path, avoiding multiple reflections and overlapping echoes, and by accounting for dispersion and similar effects.

The acousto-ultrasonic approach is among the alternatives that should be considered for material property characterization. It is specifically designed for cases where constraints imposed by pulse-echo and similar conventional ultrasonic approaches are impractical.

\section{METHODOLOGY}

Probe Configuration. - In acousto-ultrasonics the sender and receiver proves are usually coupled to the same side of the test object. (In many applications only one side will be accessible.) The probes are coupled at normal incidence to the surface of a test piece. The receiver is displaced by a fixed distance from the sender. In the limit of zero separation, this configuration reduces to conventional pulse-echo ultrasonics. The send-receive transducer pair is moved about as a unit and the test object is scanned to map material property variations, Fig. 1.

Direction criterion. - The rationale of the acousto-ultrasonic probe configuration may be understood by considering the materials characterization problem posed by fiber-reinforced composite laminates. For laminates it is desirable to measure properties with ultrasonic energy that has propagated laterally (parallel to the lateral surfaces). Transducers coupled to edges could send and receive the signals, but although thick laminates may allow effective coupling to edges, thin laminates pose a problem. (Laminate thicknesses range from a fraction of a millimeter to several centimeters.) In large laminated sheets the signal would probably be lost before reaching an opposite edge because composites are usually highly attenuating.

In laminated composite structures some or all edges may be inaccessible (e.g., cylinders, vessels, fuselages). Other examples include wood fiber boards, paper products, ropes and cables, and plate/sheet/strip stock. The 
need to use energy that has propagated parallel to major surfaces arises whether the laminates are polymer, metal, or ceramic matrix fiber reinforced composites.

Echo System. - The acousto-ultrasonic configuration assures that numerious wave interactions occur in the volume of material interrogated. Instead of consisting of a series of isolated echoes, as in pulse-echo ultrasonics, the acousto-ultrasonic signal will be much more complex. In test objects like laminated panels that have a thickness less than the spacing between probes the received signal will consist of overlapping echoes, Fig. 2. For objects having greater thicknesses echoes will tend to separate due to delayed arrivals of individual echoes. Despite its complexity the acousto-ultrasonic signal can be readily analyzed to provide information about lateral property variations. (Signal analysis methodologies are discussed later.)

Transducers. - In current practice piezoelastic probes are coupled directly to the surface of a test object. An alternative, based on contactless lasers probes will be discussed later. It is important that the sending transducer have a spectral bandwidth sufficient to excite all the frequencies needed to interrogate the material. The character of the acousto-ultrasonic signal and the data that can be extracted will depend rather heavily on the spectral response and sensitivity of the receiving probe.

For many graphite fiber polymer matrix composite laminates both the sender and receiver may be broadband $2 \mathrm{MHz}$ (megahertz) transducers. A bandwidth of about $1 \mathrm{MHz}$ may be adequate to characterize these materials. Experimental determination of appropriate transduce properties should be made for each new structure. In highly attenuating materials the receiver may need to be a sensitive transducer of the type used for acoustic emissions.

Coupling. - The acousto-ultrasonic technique depends strongly on establishing reproducible probe coupling. Otherwise, signal modulations due 
to material variations become confused with those due to coupling variations. Probes are usually coupled to a surface with a thin film of fluid (glycerin, gel, silicone grease, and shear wave couplant have been found useful). Enough pressure has to be applied to eliminate unwanted reverberations within the couplant. In addition, deleterious effects of surface roughness must be overcome. Similar precautions are needed with dry coupling which usually involves a thin elastomer buffer (e.8., silicone rubber) bonded to the transducer wearplate.

Extended Scanning. - Scanning is done by intermittently lifting and recoupling the probes. There are obvious disadvantages to the intermittent contract required with direct coupled (dry or fluid) probes. The potential need to scan large surface areas demands probes that can be readily moved about. Using probes with the piezocrystal mounted in the hub of a rubber-rimmed wheel allows continuous rolling-contact scanning. Even then, great care has to be taken to ensure that coupling variations are insignificant.

Laser Methods. - The prospect of contactless laser probes, particularly for scanning large and complex surfaces, is very attractive. 10,11 Use of lasers to excite and acquire acousto-ultrasonic signals does not eliminate potential coupling problems because the signals are still influenced by surface roughness and also emissivity, reflectivity, and other thermal and optical factors.

Probe Accommodation. - Certain accommodations may be required for either contact or laser probes to overcome coupling and surface access problems. This can entail surface preparation or even changes in part geometry and design. Insertion of sufficient laser thermal energy may ultimately depend on adding sacrificial layers (e.8., fluids, plating). Extraction of signals by means of 
interferometric or other methods may depend on affixing reflecting layers or echelle (or blazed) diffraction gratings. 12,13

Alternative Methods. - There are alternatives to the acousto-ultrasonic configuration, for example, the use of closely-spaced angle beam transducers in contact with the surface. ${ }^{14}$ similar measurements can be made with immersion scans based on leakly Lamb waves ${ }^{15}$ that arise from radiation that propagates laterally within thin laminates. Experience and results with the acousto-ultrasonic method suggest that angle beam transducers are not necessary and immersion needed by leakly waves can be avoided.

\section{FUNDAMENTAL HYPOTHESIS}

Conditional statement. - The ultimate purpose of acousto-ultrasonic approach is to rate relative efficiency of stress wave energy propagation in a material. If the material is subject to brittle or quasi-brittle failure but exhibits efficient stress wave energy transfer, then it will exhibit higher extrinsic strength and fracture resistance. This does not necessarily apply to materials that can sustain plastic deformation or slow crack growth. ${ }^{1}$

For many materials, such as fiber reinforced composites, better stress wave energy transfer means better transmission of dynamic strain, better load distribution, greater strength, and greater fracture resistance. In these cases the hypothesis is that increased energy flow (either stress or strain energy) corresponds to increased strength and fracture resistance, especially when precursor conditions for fast, brittle fracture exist. This hypothesis is based on the "stress wave interaction" concept which holds that spontaneous stress waves at the onset of fracture promote rapid crack growth unless their energy is dissipated in other ways. ${ }^{16,17}$ Prompt and efficient flow of stress wave energy away from crack nucleation sites is desired when the energy cannot be absorbed locally without cracking. 
Stress Wave Evaluation. - Acousto-ultrasonic measurements are made by means of a stress wave factor (SWF). The SWF is used to quantify acousto-ultrasonic signals for comparison with variations in mechanical properties like strength and fracture resistance. The SWF will indicate regions where strain energy is likely to concentrate and result in crack nucleation and fracture.

SWF and Attenuation. - Lower values of the SWF generally correspond to regions of higher attentuation. Indeed, the dominant effect measured in acousto-ultrasonics is relative attenuation. When properly measured, any magnitude variations of the acousto-ultrasonic signal will depend primarily on material factors that govern attenuation: microstructure, morphology, porosity, bond quality, cure state, microcracks, and so on. The acousto-ultrasonic approach assumes that these factors similarly affect the natural stress waves that arise during dynamic loading, deformation, and crack nucleation.

Stress Wave simulation. - The nature and configuration of acousto-ultrasonic probes are selected to simulate the frequency content of spontaneous stress (strain) waves that arise at the onset of microfracture, crack nucleation, deformation, etc. If this is accomplished, then the acousto-ultrasonic approach should measure the effects of factors that govern relative efficiency of strain energy transfer. Accordingly, regions that exhibit high values of the SWF would also exhibit enhanced stress wave energy flow. Conversely, low values of SWF would indicate places where the dynamic strain energy is not effectively dissipated or redistributed (with resultant deformation or fracture).

\section{STRESS WAVE FACTOR (SWF)}

General Note. - The SWF may be defined in a variety of ways. The ones mentioned here are based directly on acoustic emission practice (e.g., ringdown 
count, peak voltage, energy)..$^{5}$ This is appropriate because acousto-ultrasonic signals are usually quite similar to acoustic emission signals. The formulation of an expression for the SWF depends on which features in a waveform are most relevant to a given probe configuration, material, or structure geometry.

Ringdown SWF. - Acousto-ultrasonic signals that resemble acoustic emission bursts are readily characterized by a ringdown count or count rate. In the former case the SWF is formulated as,

$$
\mathrm{SWF}=\mathrm{E}_{\mathrm{c}}=\mathrm{PRC}
$$

where, $P$ is the repetition rate of an ultrasonic pulser, $R$ is the reset time, and $C$ is the digital counter output. A threshold voltage setting is the basis for counting the number of ringdown oscillations per waveform. Defined this way, the SWF measures relative signal strength. The threshold voltage is usually set at just above noise level. The pulse repetition rate, $P$, is set so that each signal rings down below the threshold before a new one starts. The reset time, $R$, allows averaging a predetermined number of signals into the count, $C$.

Ringdown oscillations toward the end of a signal might be more characteristic of the transducer than the material (i.e., ringdown in undampened piezotransducers). Trailing oscillations might also be reflections from regions just outside the volume between the sending the receiving probes. Therefore, it may be necessary to increase threshold level slightly or to truncate the ringdown counting time zone. In either case threshold and reset criteria should be based on experimental feedback.

Peak Voltage SWF. - By using peak detection the SWF may be defined as,

$$
S W F=E_{v}=V_{\max }
$$

where, the SWF is base on the maximum (max) voltage swing. This assumes that dominant oscillations always represent any material variations. But, smaller 
oscillations that precede or follow may be more representative. An appropriate alternative based on peak voltage might be the measurement of signal rise time or signal decay time (as in acoustic emission practice).

The pulse repetition rate, $P$, and reset time, $R$, settings mentioned above for ringdown SWF still apply for measuring peak voltage SWF and also for the energy SWF, described next.

Energy SWF. - The relative energy of the acousto-ultrasonic signal can be defined in the time domain as,

$$
\text { SWF }=E_{t}=\left(v_{r m s}\right)^{2}=\frac{1}{T} \int_{t_{1}}^{t} v^{2} d t
$$

where, the SWF is based on root mean square (rms) voltage, $T$ is a time interval $\left(t_{1}\right.$ to $\left.t_{2}\right), t$ is time, and $v$ is time-varying voltage. An equivalent frequency domain definition of the SWF in terms of the root mean square of the power spectrum is,

$$
S W F=E_{f}=\left(s_{r m s}\right)^{2}=\frac{1}{F} \int_{t_{1}}^{t} s^{2} d f
$$

where, $F$ is a frequency interval $\left(f_{1}\right.$ to $\left.f_{2}\right), f$ is frequency, and $s$ is a function of frequency. Although it is unnecessary to set a threshold voltage, it is still necessary to specify the size and location of the interval (i.e., $T$ or $F$ ) in the time or frequency domain that will most closely associate with material variations. This suggests the need to experimentally determine specific time or frequency intervals for each new material, structure, and probe configuration.

Using the previous definitions of the SWF, Eqs. (1) to (4), it is usually better to normalize values of quantities like $E_{c}, E_{t}$, or $F_{f}$ for comparison with material property variations. It has been found practical to normalize 
against the maximum asymptotic value found for these quantities for a given material, structure, and probe configuration. 7,18

SIGNAL AMALYSIS

General Observations. - The envelop of the acousto-ultrasonic time domain waveform usually exhibits complicated amplitude variations, Fig. 3 . And, the corresponding frequency spectrum usually exhibits a numerous prominent

frequency components. These time and frequency domain features are related to one or more material and structural factors: velocity, dispersion, attenuation, dynamic vibration modes, plates waves, etc. These factors are influenced in turn by the nature of the transducers, probe configurations, coupling, instrumentation, etc.

There is a need for better understanding of wave propagation factors that underlie acousto-ultrasonic waveforms. Accordingly, the problem of predicting and analyzing waveforms for various material conditions (shape, texture, isotropy) has been broached in order to satisfy this need. ${ }^{19.20}$ some insights that have been gained and improved signal analysis methods that have been proposed are discussed below.

Natural Modes. - Experimental evidence suggests that natural vibration modes and associated nodal lines on the surface of a solid will certainly affect acousto-ultrasonic measurements. ${ }^{21}$ Evaluation of the SWF can be misleading if specimen resonances are ignored or misinterpreted. Resonant frequencies and their corresponding nodal patterns can have an enormous effect on the acousto-ultrasonic waveform and on the evaluation of the SWF. Resonant frequencies due to natural vibration modes of a structure can dominate the spectral content. This is especially true when the sending transducer inputs energy at the resonant frequencies. Location of the receiver in relation to nodal lines further influences the spectrum of the acousto-ultrasonic waveform. 
Dispersive Modes. - Although the sending transducer inputs longitudinal waves perpendicular to the specimen surface, the energy radiated into the material will produce oblique reflections and shear waves. Interactions of shear and longitudinal waves with plate boundaries and with plies in laminates produced various dispersive wave modes. ${ }^{14}$ When laminate or ply thicknesses of composite structures are comparable to the ultrasonic wavelengths, several Lamb modes with different speeds propagate simultaneously. Since Lamb waves are dispersive, their phases and group velocities depend on frequency, laminate thickness, bond quality (adhesion) between plies, etc. 22,23 some Lamb modes will be excited and others will be extinguished in accordance with boundary conditions and the interlaminar bond quality in composite laminates. Factors that govern these wave modes also determine the character of the acousto-ultrasonic waveform.

Wave Paths. - It is useful to attempt to trace wave paths, to track multiple reflections, and to gauge depths of penetration. This proves to be particularly difficult in most laminated composite structures. Some investigators have inferred that the SWF is typical only of the first few plies of a laminate. ${ }^{24}$ others have held that the SWF was influenced by all plies throughout a laminate. In the latter cases it appeared that SWF was sensitive to plies at the opposite surface even in relatively thick composite laminates. 25 Ambiguities about wave paths are bothersome because waves reflected by intermediate layers and bondlines are likely to be more relevant than those from the free surface of a structure.

Problem Summary. - The acousto-ultrasonic approach attempts to ensure that interrogating waves interact freely with many material parameters. Then, a major signal analysis problem in acousto-ultrasonics is the need for separating interactive waveform components. It becomes necessary to sort out those components that are most relevant to the particular material property or 
internal condition to be assessed. Alternatively, there may be instances where is better not to separate waveform components but to deal with the whole signal as a multivariate data set. Several powerful approaches to acousto-ultrasonic signal analysis along both lines are suggested next.

Homomorphic Processing. - One of the most promising means for dealing with the signal deconvolution problem is provided by homomorphic signal processing. ${ }^{26}$ It has been successfully applied to the analysis of audio-acoustic, speech, and seismic signals. Homomorphic processing is necessary for waveforms with components whose Fourier transforms overlap. Homomorphic filters provide the means for deconvolving such waveform components, Fig. 4. A detailed discussion of homomorphic processing methodology is given elsewhere. ${ }^{27}$ It is sufficient here to note that the method should lead to improved evaluations of the SWF by isolating key components in waveforms that consist for superimposed multiple echo systems (as in thin composite laminates). Homomorphic processing should be particularly useful in identifying significant wave modes and their paths.

Partition-Regression Method. - Another methodology that has proven to be useful is based on partitioning waveforms and their spectra followed by regression analysis. ${ }^{28}$ one procedure is to divide the time and frequency domain records into a large number of equal segments. The SWF for each segment is regressed against a material property of interest to find corresponding time and frequency segments that correlate with that property. The procedure is iterated until the correlation is optimized. The basic assumption of the partition-regression method is that relevant signal components and their frequency bands can be separated with simple linear filters. 29 This is in contrast to conditions that indicate homomorphic processing. 26

When used with either Eqs. (3) or (4) the partition-regression method found corresponding time and frequency domain intervals that gave the best 
correlation with a given material property (i.e., filament-wound composite interlaminar shear strength), Fig. 5. ${ }^{30}$ An interesting outcome was that only the least prominent part of the spectrum gave the greatest correlation coefficient with shear strength. That is, while lower frequency components dominated the spectrum, only the higher frequencies varied significantly with interlaminar shear strength variations, in the experiment cited. These higher frequencies corresponded to the initial oscillations of the acousto-ultrasonic signal while lower frequencies were associated with trailing oscillations. Finite Element Vibration Analysis. - Among factors that are likely to influence the SWF are boundary conditions that govern resonant frequencies of natural vibration modes. 21 The prominent low frequency components in the previously-cited case provide an example of this situation. This indicates a need for independent means for identifying resonant frequency components. But, in heterogeneous, anisotropic materials with uniform properties this need poses a difficult problem.

Because flaw systems in composite materials can be quire complex, finite element analysis may be needed to help define inspection parameters. Accordingly, the use of finite element models has been suggested to study the effect of material anomalies and possible damage (type, severity, area) on boundary conditions and on SWF measurements. ${ }^{31}$ Finite element predictions of resonant frequencies and mode shapes can help optimize the location, configuration, and sensitivity requirements for acousto-ultrasonic probes. Developing simple analytical models that incorporate appropriate parameters should reduce trail and error while providing a rational basis for performing SWF measurements.

Method of Moments. - Simple structural geometries and boundary conditions combined with judicious selection of transducers and probe configurations may eliminate or substantially reduce ambiguous and irrelevant signal components. 
In these cases the homomorphic and partitioning methodologies may be unnecessary. Then, with simple noise elimination, the entire acousto-ultrasonic waveform can be retained and analyzed as a whole. For example, excellent correlations have been obtained with SWFs based on essentially raw total waveforms. 18,32

The method of moments invokes the use of parameters such as those used to describe distribution functions, namely location, scale, and shape parameters. ${ }^{33}$ In the frequency domain, in addition to the mean square definition given in Eq. (4), the SWF can be defined from full waveform power spectra in terms of various moments and ratios of moments: the centroid, kurtosis, skewness, standard deviation, variance. ${ }^{28}$ These quantities can be readily evaluated using digital fast Fourier transforms. ${ }^{29}$ This stratagem acknowledges the stochastic nature of attenuating interactions that shape the waveforms and also the validity of a statistical treatment of their spectra.

Pattern Recognition Method. - There are a rather large number of possible mechanical properties and morphological conditions that can affect a correspondingly large number of acousto-ultrasonic signal parameters. This suggests determining the state of a material with pattern recognition methodology. 34,35 This methodology involves statistically-based data generation, feature extraction, and classification. By using samples containing known states (i.e., training samples) significant discriminatory pattern vectors can be defined and used for feature extraction, Fig. 6. Then, as described in detail elsewhere, ${ }^{34}$ the most likely states in an unknown material can be identified and associated with particular acousto-ultrasonic signal parameters. This "adaptive learning" methodology has been successfully used for analyzing acoustic emission signals and may be a practical alternative to the apriori modeling demanded by the finite element approach mentioned above. 
Auxiliary Measurements. - Additional ultrasonic measurements may occasionally be needed to corroborate or clarify acousto-ultrasonic measurements. Velocity or attentuation measurements using conventional time-of-flight or pulse-echo methods, respectively, are likely to be quite useful for independently evaluating certain material parameters (e.g., elastic constants). 36,37 Combined with acousto-ultrasonic measurements they can help remove ambiguities and aid in signal analysis. As an example, swF values combined with surface-parallel velocity measurements gave better correlations with composite laminate shear strength than either the SwF or velocity alone. ${ }^{18}$

\section{EXEMPLARY FINDINGS}

General Findings. - There are now abundance examples of successful applications that show the viability of acousto-ultrasonics for measuring mechanical strength variations in structural composites and for measuring degradation from cyclic fatigue and impact damage. Acousto-ultrasonics has also been used to measure adhesive bond strength, ${ }^{38,39}$ polymer composite cure state, ${ }^{40}$ filler content in wood and paper produces, 41 wire rope strength, ${ }^{42}$ and porous metal diffusion bond quality. ${ }^{43}$ Details for some relevant experimental findings are reviewed next.

SWF Hypothesis. - Perhaps the best demonstration of the previously-stated hypothesis regarding SWF measurement of relative strain energy transfer and ehance relative strength is obtained with unidirectional composite laminates. It is easy to show that the SWF is sensitive to fiber direction and that the SWF is greatest in the fiber direction and least perpendicular to the fiber direction. This agrees with the fact that ultimate tensile strength is also greatest in the fiber direction. The SWF measured perpendicular to the fiber direction will have a low value corresponding to low ultimate strength in that direction (because the load is then sustained only by the matrix.) 
When fiber orientations are mixed, the magnitude of the SWF will vary accordingly, Fig. 7. 44 In a laminate consisting of alternating cross-ply layers the $0^{\circ}$ plies will transmit stress wave energy more efficiently than $45^{\circ}$ plies which in turn are more efficient than $90^{\circ}$ plies. The SWF will rank laminates according to the proportion of $0^{\circ}$ plies aligned with the load direction.

Failure Site Location. - Mapping SWF variations along the load axis of tensile specimens is an effective way to identify weak regions. 44,45 These regions will usually have the lowest SWF values. This has proved to be true in a variety of composite laminate tensile specimens having mixed fiber orientations. It is noteworthy that that composites subjected to acousto-ultrasonic evaluation the potential failure loci gave no prior indication of overt flaws such as delaminations. Any flaws, if present, were so minute or diffuse that they were sensed only as low values of the SWF (or greater ultrasonic attenuation).

Apparently, there is a close correspondence between the SWF and stiffness in composite laminates. Moire interferometry has shown that variations in strain during axial loading agree rather closely with SWF variations along the load axis. Local regions of low SWF correspond to high local displacement in moire fringe patterns and also to failure loci when specimens are loaded to failure. 24

Degradation Assessment. - Among the most useful aspects of acousto-ultrasonics is the ability to assess degradation states in a material. In fiber reinforced composites degradiation can result from moisture absorption, chemical attack, cyclic fatigue, or impact damage. Fatigue and impact damage although subtle can significantly change material properties by reducing stiffness, strength, and, ultimately, curtail the service life of composite structures. 
The SWF is sensitive to progressive degradation in composite laminates subjected to cyclic fatigue. A close relation between decreasing SWF and decreasing stiffness due to cyclic fatigue of composite laminated has been demonstrated. $^{32}$ Indeed, the SWF appears to be sensitive indicator of local fatigue damage when compared to overall stiffness reduction as measured by the secant modulus, Fig. 8. Apparently, changes in the SWF are related to the accumulation of damage primarly in the form of matrix crazing and fiber breakage distributed throughout the volume being fatigued. ${ }^{36,46}$ It has been noted that systematic shifts in certain spectral components of the acousto-ultrasonic waveform tend to accompany fatigue.

The SWF is also a sensitive indicator of accumulated degradation in composite laminates subjected to impact damage, Fig. 9.47 Changes in the SWF correspond closely to linear reduction in elastic modulus, ultimate tensile strength, and toughness exhibited by unidirectional laminates that sustained increasing number of impacts. In laminates subjected to combined fatigue and impact it was found that resultant reductions in fatigue life were accompanied by abrupt reductions in the magnitude of the SWF. ${ }^{48}$ Correspondences were found between the SWF, the extent and nature of impact or fatigue damage (ranging from microcrack populations to fractured fibers), and changes in load response and life.

Interlaminar Strength. - High interlaminar strength in composite laminates and high adhesive bond strength in joints are pivotal to structural integrity. Nondestructive measurement of these interface properties is very difficult with conventional NDE approaches because poor bond quality does not always manifest itself as readily-found sets of discrete flaws or discontinuities. Usually, conventional NDE methods give only qualitative results.

The acousto-ultrasonics approach has proven particularly useful for quantifying relative bond strength. Excellent correlations have been obtained 
between interlaminar shear strength in composite laminates as measured by mechanical bend tests and the SWF, Fig. $10^{18,30}$ similarly, good correlations have been obtained between the peel-test strength of adhesive bonds and the SWF. 38 Apparently, the acousto-ultrasonic wave interactions are sensitive to the properties of interfaces.

Flaw Detection. - Although the emphasis here is on materials characterization, nothing precludes using acousto-ultrasonics for detecting delaminations, hidden impact damage areas, or other overt flaws. 49,50 Indeed, acousto-ultrasonics or other NDE methods should be used to identify and help eleminate items that contain obviously harmful flaws.

\section{CONCLUSIONS}

The sensitivity of the acousto-ultrasonic approach for detecting and quantifying subtle but significant variations in the strength and fracture resistance of fiber reinforced composites has been experimentally demonstrated. This is somewhat remarkable because, for the most part, it has been accomplished with relatively unsophisticated signal processing and analysis procedures. Nevertheless, the viability of the acousto-ultrasonic approach certainly warrants the development of more advanced instrumentation and signal analysis methodology, along the lines suggested in this paper. Results obtained thus far with polymer matrix composites indicate that that acousto-ultrasonic approach should prove useful for other composite materials, e.8., fiber reinforced metal an ceramic matrix composites. This view follows from similarities in the nature of these materials. Based on the concepts and findings discussed in this paper, the acousto-ultrasonic approach should be considered whenever there is a need to assess integrated defect states and related strength and fracture resistance in composites. The approach merits special consideration to quantify any damage or property degradation after composites are exposed to hostile environments. 


\section{REFERENCES}

1. Kanninen, M.F., and C.H. Popelar, Advanced Fracture Mechanics, Oxford University Press, New York, 1985, pp. 392-432.

2. Vary, A., "A Review of Issues and Strategies in Nondestructive Evaluation of Fiber Reinforced Structural Composites," New Horizons - Materials and Processes for the Eighties, National SAMPE Technical Conference Series, vol. 11, SAMPE, Azusa, CA, 1979, pp. 166-177.

3. Vary, A., and K.J. Bowles, "An U1trasonic-Acoustic Technique for Nondestructive Evaluation of Fiber Composite Quality," Polymer Engineering and Science, Vol. 19, April 1979, pp. 373-376.

4. Ruud, C.O., and R.E. Green, Jr., eds., Nondestructive Methods for Material Property Determination, Plenum Press, New York, 1984.

5. Matthews, J.R., (ed.), Acoustic Emission, Gordon and Breach Science Publishers, New York, 1983.

6. Vary. A., "Acousto-Ultrasonic Characterization of Fiber Reinforced Composites," Materials Evaluation, Vol. 40, May 1982, pp. 650-654, 662 .

7. Vary, A., "Concepts and Techniques for Ultrasonic Evaluation of Material Mechanical Properties," Mechanics of Nondestructive Testing, $w$. W. Stinchcomb., ed., Plenum Publishing, New York, 1980, pp. 123-141.

8. Green, R.E., Jr., "Basic Wave Analysis of Acoustic Emission," Mechanics of Nondestructive Testing, W.W. Stinchcomb, ed., Plenum Press, Hew York, 1980, pp. 55-76.

9. Vary, A., U1trasonic Measurement of Material Properties," Research Techniques in Mondestructive Testing, Vol. 4, R. S. Sharpe, ed., Academic Press, London, England, 1980, pp. 159-204.

10. Monchalin, J-P., and R. Heon, "Laser Ultrasonic Generation and Optical Detection with a Confocal Fabry-Perot Interferometer," Materials Evaluation, Vol. 44, Sept. 1986, pp. 1231-1237. 
11. Hutchins, D.A., R.J. Dewhurst, S.B. Palmer, and C.B. Scruby, "Laser Generation as a Standard Acoustic Source in Metals," Applied Physics Letters, Vol. 38, May 1, 1981, Pp. 677-679.

12. Sarrafzadeh-Khoee, A. and J.C. Duke, Jr., "Noncontacting Detection in Ultrasonic Nondestructive Evaluation of Materials: Simple Optical Sensor and Fiber-optic Interferometric Application," Review of Scientific Instruments, Vol. 57, Sept. 1986, pp. 2321-2325.

13. Sarrafzadeh-Khoee, A., and J.C. Duke, Jr., "Small In-Plane/Out-of-Plane Displacement Measurement Using Laser-Speckle Interferometry," Experimental Techniques, Vol. 10, Oct. 1986, pp. 18-61.

14. Krautkramer, J., and Krautkramer, H., Ultrasonic Testing of Materials, 2nd ed., Springer-Verlag, New York, 1969.

15. Bar-Cohen, Y., and D.E. Chimenti, "Detection of Porosity in Composites Using Leaky Lamb Waves," Proceedings of the Eleventh World Conference on Nondestructive Testing, Vol. III, Taylor Publishing, Dallas, 1985, Pp. 1661-1668.

16. Kolsky, H., Stress Waves in Solids, Dover, New York, 1963.

17. Vary, A., "UItrasonic Nondestructive Evaluation, Microstructure, and Mechanical Property Interrelations," NASA TM-86876, 1984.

18. Vary, A., and K.J. Bowles, "Ultrasonic Evaluation of the Strength of Unidirectional Graphite/Polyimide Composites," in Proceeding of the Eleventh Symposium on Nondestructive Evaluation, Southwest Research Institute, San Antonio, TX, 1977 Pp. 242-258.

19. Williams, J.H., Jr., H. Karagulle, and S.S. Lee, "Ultrasonic Input-Output for Transmitting and Receiving Longitudinal Transducers Coupled to Same Face of Isotropic Elastic Plates," Materials Evaluation, Vol. 40, May 1982, pp. 655-662. 
20. Williams, J.H., Jr., S.S. Lee, and H. Karagulle, "Input-Output Characterization of an Ultrasonic Testing System by Digital Signal Analysis," Analytical Ultrasonics in Materials Research and Testing, A. Vary, ed., NASA CP-2383, 1986, Pp. 311-339.

21. Williams, J.H., Jr., E.B. Kahn, and S.S. Lee, "Effects of specimen Resonances on Acoustic-Ultrasonic Testing," Materials Evaluation, Vol. 41, Dec. 1983, pp. 1502-1510.

22. Hemann, J.H., and G.Y. Baaklini, "The Effect of Stress on Ultrasonic Pulses in Fiber Reinforced Composites," SAYPE Journal, Vol. 22, July-Aug., 1986, pp. 9-13.

23. Rokhlin, S.I., "Adhesive Joint Evaluation by Ultrasonic Interface and Lamb Waves," Analytical Ultrasonics in Materials Research and Testing, A. Vary, ed., NASA CP-2383, 1986, pp. 299-310.

24. Govada, A.K., J.C. Duke, Jr., E.G. Henneke, II, and W.E. Stinchcomb, "A Study of the Stress Wave Factor Technique for the Characterization of Composite Materials," NASA CR-174870, 1985.

25. Kautz, H.E., "Ultrasonic Evaluation of Mechanical Properties of Thick, Multilayered, Filament Wound Composites," NASA TM-87088, 1985.

26. Karagulle, H., J.H. Williams, Jr., and S.S. Lee, "Application of Homomorphic Signal Processing to Stress Wave Factor Analysis," Materials Evaluation, Vol. 43, Oct. 1985, pp. 1446-1454.

27. Oppenheim, A.V., and A.S. Willsky, with Young, I.T., Signals and Systems, Prentice-Hall, Englewood Cliffs, New Jersey, 1983.

28. Johnson, R.A., and D.W. Wichern, Applied Multivariate Statistical Analysis, Prentice-Hall, Englewood Cliffs, New Jersey, 1982.

29. Bracewel1, R.N., The Fourier Transform and Its Applications, McGraw-Hill, New York, 1978. 
30. Kautz, H.E., "Acousto-Ultrasonic Verification of the Strength of Filament Wound Composite Material," NASA TM-88827, 1986.

31. Rebello, C.J., and J.C. Duke, Jr., "Factors Influencing the Ultrasonic Stress Wave Factor Evaluation of Composite Material Structures," Journal of Composites Technology and Research, Vol. 8, Spring, 1986, pp. 18-23.

32. Duke, J.C., Jr., E.G. Henneke, II, W.W. Stinchcomb, and K.L. Reifsnider, "Characterization of Composite Materials by Means of the Ultrasonic Stress Wave Factor," Composite Structures, 2, I.H. Marshall, ed., Applied Science Publishers, London, England, 1984, pp. 53-60.

33. Govada, A., E.G. Henneke, II, and R. Talreja, "Acousto-Ultrasonic Measurements to Monitor Damage During Fatigue of Composites," 1984 Advances in Aerospace Sciences and Engineering," $U$. Yuceoglu and R. Hesser, eds., American Society of Mechanical Engineers, New York, 1984, pp. 55-60.

34. Williams, J.H., Jr., and S.S. Lee, "Pattern Recognition Characterization of Micromechanical and Morphological Materials States via Analytical Quantitative Ultrasonics," Analytical Ultrasonics in Materials Research and Testing, A. Vary, ed., MASA CP-2382, 1986, Pp. 193-205.

35. Andrews, H.C., Introducton to Mathematical Techniques in Pattern Recognition, Wiley-Interscience, John Wiley and Sons, New York, 1972. 36. Williams J.H., Jr., and B. Doll, "Ultrasonic Attenuation as an Indicator of Fatigue Life of Graphite Fiber Epoxy Composite," Materials Evaluation. Vol. 38, May 1980, pp. 33-37.

37. Fitting, D.W., and L. Adler, "Ultrasonic Spectral Analysis for Nondestructive Evaluation, Plenum Press, New York, 1981.

38. doe Reis, H.L.M., L.A. Bergman, and J.H. Bucksbee, "Adhesive Bond Strength Quality Assurance Using the Acousto-U1trasonic Technique," The British Journal of Nondestructive Testing, Vol. 28, Nov. 1986, pp. 357-358. 
39. dos Reis, H.L.M., and H.E. Kautz, "Nondestructive Evaluation of Adhesive Bond Strength Using the Stress Wave Factor Technique," Journal of Acoustic Emission, Vol. 5, Oct.-Dec. 1986, pp. 144-147.

40. Hinrichs, R.J., and J.M. Thuen, "Control System for Processing Composite Materials," U. S. Patent No. 4,455,268, June 1984.

41. dos Reis, H.L.M., and D.M. McFarland, "On the Acousto-Ultrasonic Characterization of Wood Fiber Hardboard," Journal of Acoustic Emission, Vol. 5, April-June 1986, Pp. 67-70.

42. dos Reis, H.L.M., and D.M. McFarland, "On the Acousto-Ultrasonic Mon-Destructive Evaluation of Wire Rope Using the Stress Wave Factor Technique," The British Journal of Nondestructive Testing, Vol. 28, May 1986, Pp. 155-156.

43. Vary, A., P.E. Moorhead, and D.R. Hull, "Metal Honeycomb to Porous Wireform Substrate Diffusion Bond Evaluation," Materials Evaluation, Vol. 41, July 1983, Pp. 942-945.

44. Vary. A., and R.F. Lark, "Correlation of Fiber Composite Tensile Strength with the Ultrasonic Stress Wave Factor," Journal of Testing and Evaluation, Vol. 7, July 1979, pp. 185-191.

45. Duke, J.C., Jr., E.G. Henneke, II, and W.W. Stinchcomb, "Ultrasonic Stress Wave Characterization of Composite Materials," MASA CR-3976, 1986.

46. Williams, J.H., Jr., H. Yuce, and S.S. Lee, "Ultrasonic and Mechanical Characterizaton of Fatigue States of Graphite Epoxy Composite Laminates," Materials Evaluation, Vol. 40, April 1982, pp. 560-565.

47. Williams, J.H., Jr., and N.R. Lampert, "Ultrasonic Evaluation of Impact-Damaged Graphite Fiber Composite," Materials Evaluation, Vol. 38, Dec. 1980 , Pp. 68-72. 
48. Nayeb-Hasemi, N., Cohen, M.D., Zotos, J., and Poormand, R., "Nondestructive Evaluation of Graphite/Epoxy Composite Materials Subjected to Combined Fatigue and Impact," Proceedings of the International Conference and Exposition on Fatigue, Corrosion Cracking, Fracture Mechanics, and Failure Analysis, American Society for Metals, Cleveland, 1986. Report Mo. WU-ME-101, Northeastern University, Boston 1985).

49. Green, J.E., and J. Rodgers, "Acousto-Ultrasonic Evaluation of Impact-Damaged Graphite Epoxy Composites," Materials Overview for 1982, SAMPE, AzUsa, CA, 1982, pP. 428-439.

50. Green, J.E., J.D. Carlyle, and P. Kukuchek, "Impact Damaged Epoxy Composites: Impact Testing and NDT Evaluation," $\underline{\mathrm{RP} / \mathrm{C} \cdot 83 \text { : Composite }}$ Solutions to Material Challenges, Society of the Plastics Industry, New York, 1983, Session 21-G, Pp. 1-6. 


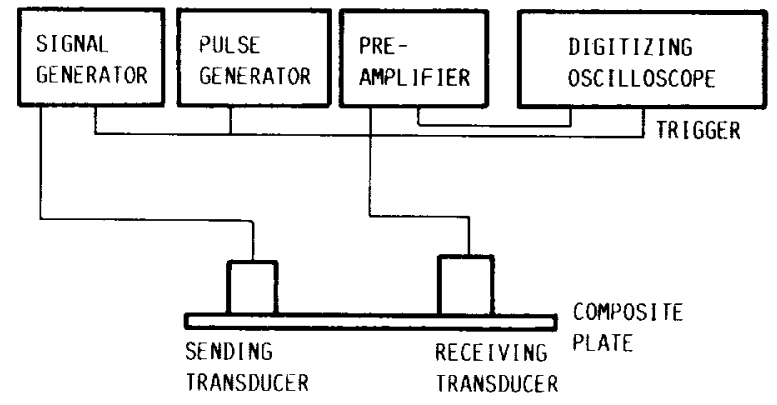

FIGURE 1. - BASIC PROBE CONF IGURATION AND INSTRUMENTATION FOR ACOUSTO-ULTRASONIC MEASUREMENTS. DIGITIZING OSCILLOSCOPE IS USED TO FEED TIME DOMAIN SIGNALS (WAVEFORMS) TO COMPUTER FOR ANALYSIS AND EVALUATION OF ACOUSTO-UL TRASONIC PARAMEIERS [45].

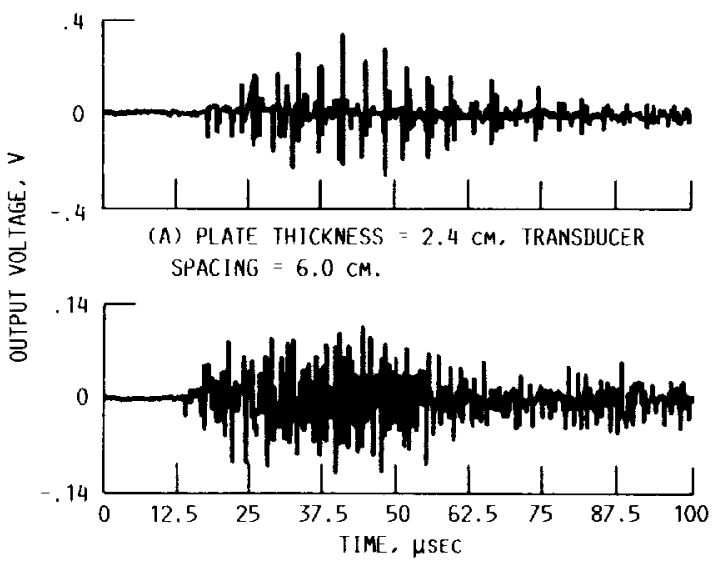

(B) PLATE THICKNESS $=1.2 \mathrm{CM}$, TRANSDUCER SPACING $=6.2 \mathrm{cM}$.

FIGURE 2, - ACOUSTO-UL IRASONIC WAVEFORMS FROM ALUMINUM PLATES WITH TWO DIFFERENT THICKNESS AND WITH TWO DIFFERENT SPACINGS BETWEEN SENDING AND RECEIV ING IRANSDUCERS. THE SENDER AND RECEIVER HAD BANDWIDTHS OF APPROXIMATELY 1 MHZ AT CENTER FREQUENCIES IN THE RANGE FROM 1.3 IO $1.7 \mathrm{MHZ}$ [26].

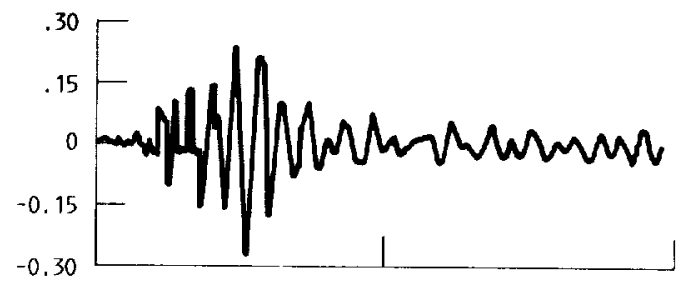

(A) ORIGINAL WAVEFORM.

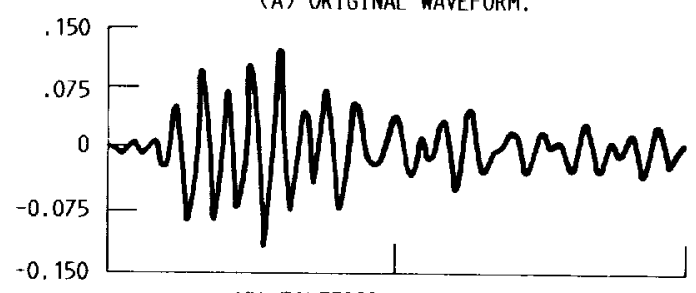

(B) FILTERED 0 TO $0.25 \mathrm{MHz}$.
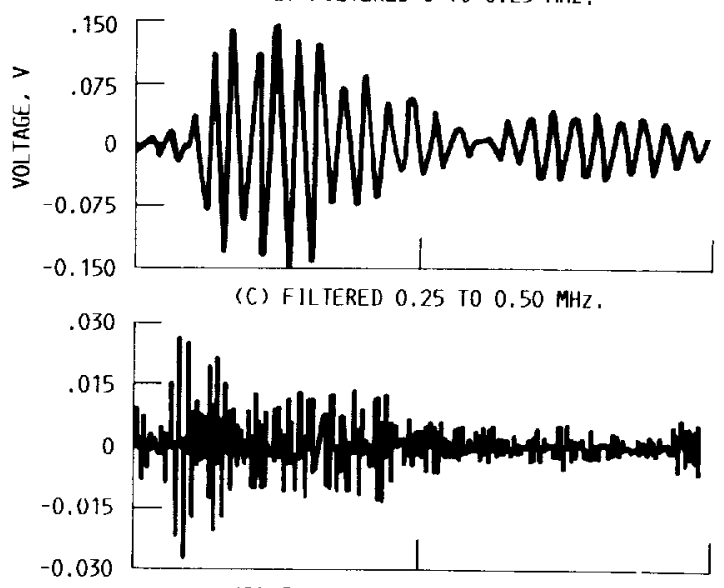

(D) FIL TERED 0.50 T0 $0.75 \mathrm{MHz}$.

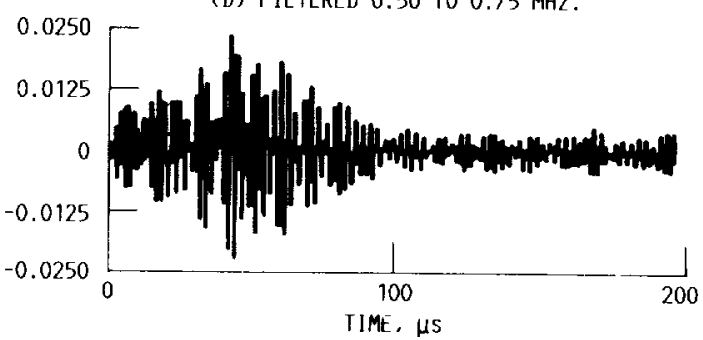

(E) FILTERED 0.75 TO $1.0 \mathrm{MHz}$

F1GURE 3. ACOUSTO-ULTRASONIC WAVEFORMS IROM A FILAMENT WOUND COMPOSITE BEND BAR WITH A THICKNESS OF $0.65 \mathrm{CM}$ AND 5 AL TERNATING CROSS-PLIES. THE ORIGINAL WAVEFORM OF THE RECEIVED SIGNAI (A) WAS PASSED THROUGH FOUR FILTERS (B) IHROUGH (E) TO ILLUSTRATE DIVERSE FREQUENCY AND MODAL COMPONENTS PRESENT 125]. 


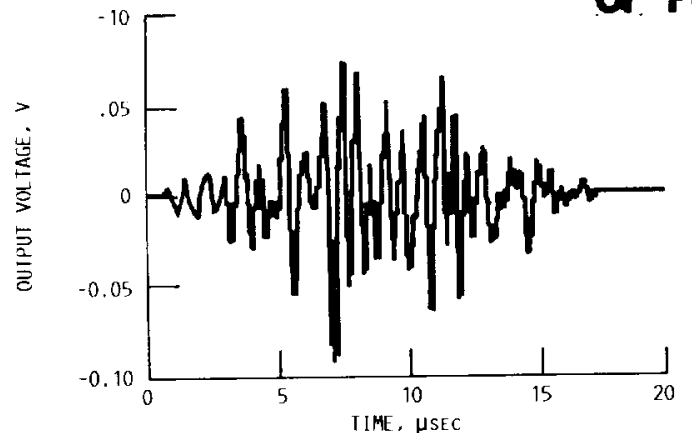

(A) WINDOWED WAVEFORM.

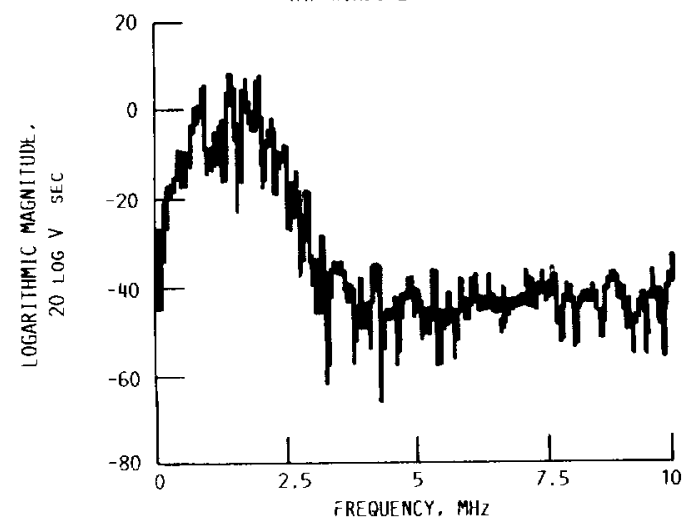

(B) LOG SPECTRUM.

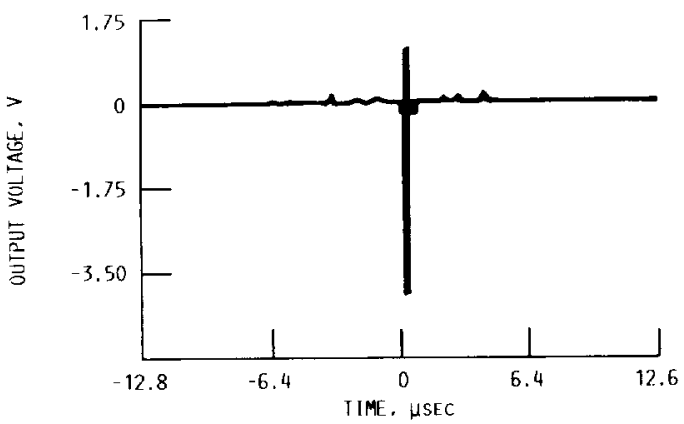

(C) CEPSTRUM WINDOW.

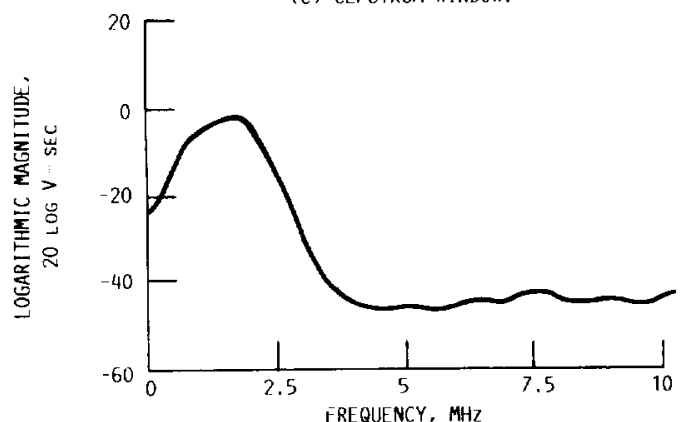

(D) SMOOTHED SPECTRLMM

FIGURE 4. - HOMOMORPHIC ANALYSIS OF AN ACOUSTOULTRASONIC WAVEFORM. A HAMHING WINDOW IS USED TO SELECT A PORTION (A) OF THE ORIGINAL WAVEFORM FOR ANALYSIS. RAPID VARIATIONS IN THE LOG SPECTRUM (B) ARE. REMOVED BY CEPSTRUM WINDONING (C) TO GET SMOOIHED LOG SPECTRUM (D). PROCEDURE IS REPEATED TO CHARACTERIZE LOG SPECTRA OF VARIOUS REFLECTIONS COMPRISING THE WAVEFORM. THE ANALYSIS PROCEFDS BY COMPARISON WITH CHARACIERISIIC LOG SPECIRA OF HOMOMORPHIC SIGNAL COMPONENTS WITH KNOWN MODES AND RAY PATHS IN COMPANION SAMPLE 1261 .
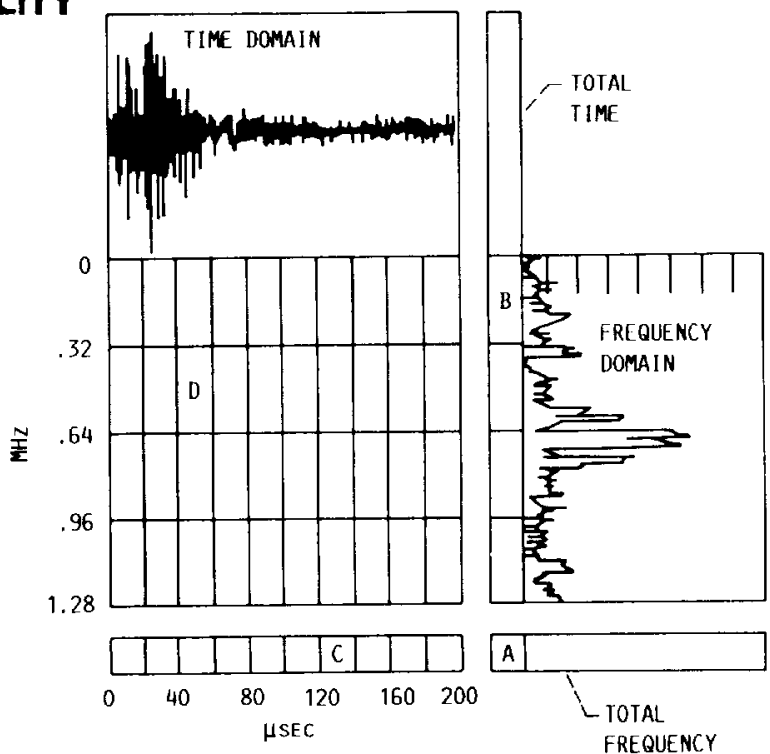

FIGURE 5, - WAVEFORM PARIITIONING SCHEME FOR STRESS WAVE FACTOR (SWF) CALCULATIONS AND FORMAT FOR PRESENTING REGRESSION COEFFICIENTS. BLOCK "A" HOLDS THE REGRESSION COEFFICIENT BASED ON THE SWF FOR THE TOTAL WAVEFORM AND SPECTRUM. BLOCK "B" IS FOR IHE FREQUENCY INTERVAL O TO $0.32 \mathrm{MHZ}$ AND TOTAL WAVEFORM. BLOCK "C" IS FOR THE TIME INTERVAL 120 T0 $140 \mu \mathrm{s}$ AND TOTAL SPECTRUM. BLOCK "D" REPRESENIS PARTITIONS OF BOTH THE WAVEFORMS AND SPECTRA. BLOCKS ARE FILLED WITH COEFFICIENTS OBTAINED BY REGRESSING SWF VALUES WITHIN THE INTERVALS AGAINST A MAIERIAL PROPERTY TO FIND THE BEST CORRELATION WITH THAT PROPERTY 1301.

FEATURE SPACE

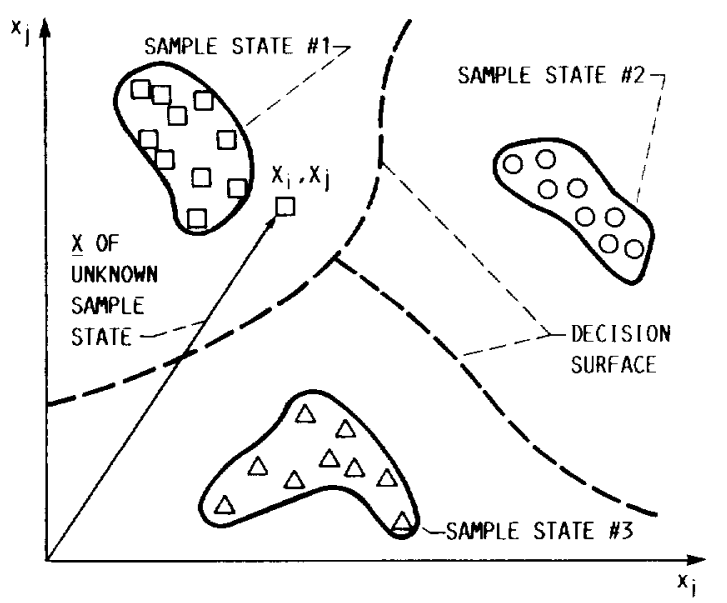

FIGURF 6. - SCHEMATIC ILLUSTRATION OF DECISION SURFACES SEPARATING FEATURE SPACE INTO REGIONS CORRESPONDING TO DISTINCT SAMPLE STATES ARRIVED AT BY ADAPTIVE LEARNING METHODOLOGY. PATTERN RECONGNITION ANALYSIS IS USED TO CLASSIFY UNKNOWN SAMPLE AS BELONGING TO A PARTICUIAR SAMPLE STATE [34]. 

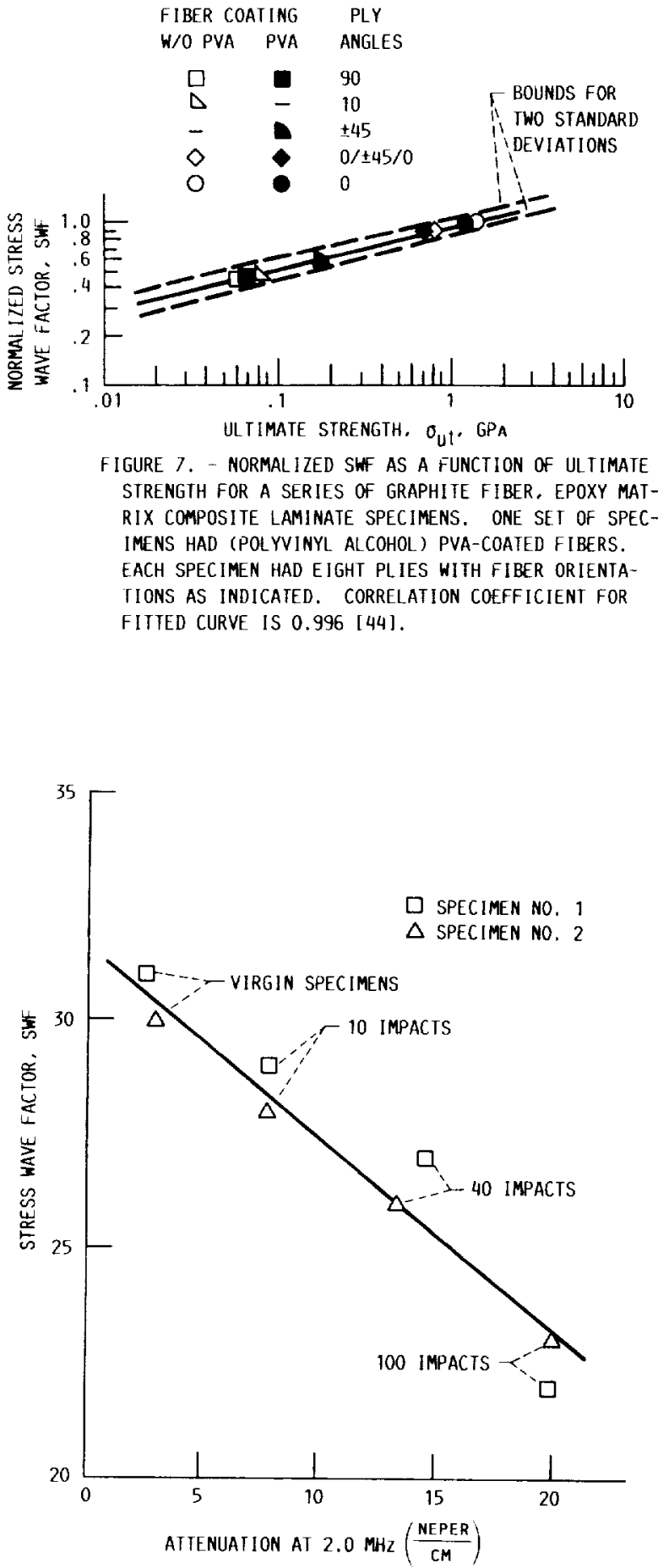

FIGURE 9. - STRESS WAVE FACTOR (SWF) VERSUS THROUGHTRANSMISSION ULTRASONIC ATTENUAIION AT IMPACT SIIE OF 10-PLY UNIDIRECIIONAL GRAPHITE/EPOXY COMPOSITE LAMINATE SPECIMENS [47].

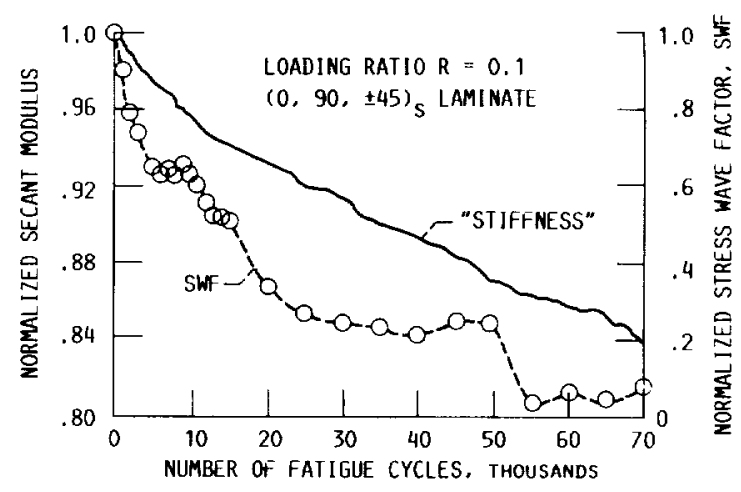

FIGURE 8. - CONVARIATION OF NORMALIZED SWF AND LONGITUDINAL SECANT MODULUS WITH FATIGUE DAMAGE IN GRAPHITE/EPOXY FIBER COMPOSITE LAMINATE. DIFFERENCE IN SLOPES IS BECAUSE SECANT MODULUS IS FOR FULL GAUGE LENGIH WHILE SWF IS FOR LOCAL PORTION OF TEST SPECIMEN [32].

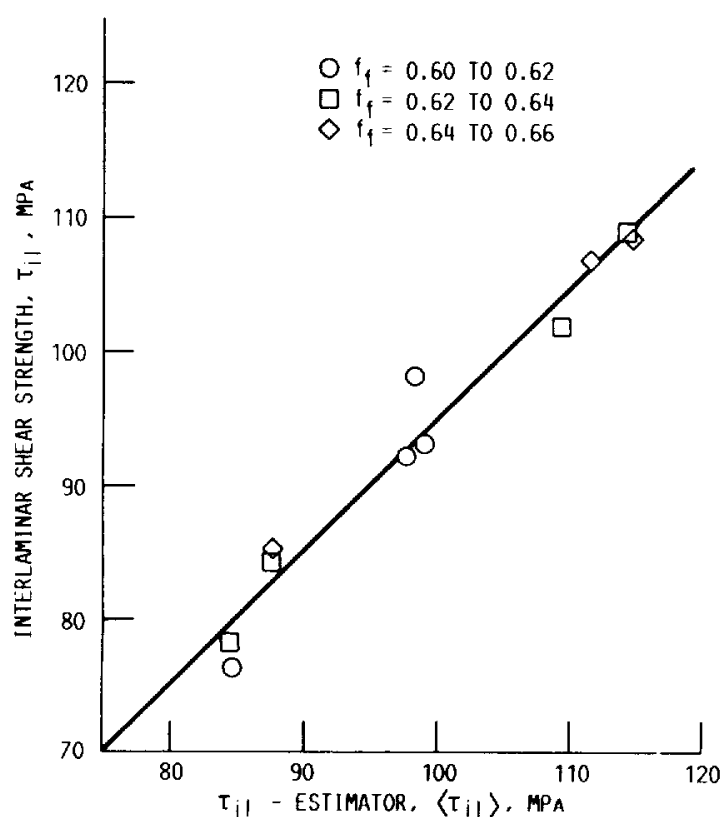

FIGURE 10. - CORRELATION BETWEEN MEASURED INTERLAMINAR SHEAR STRENGTH AND ITS ACOUSTO-UL TRASONIC ESTIMATOR FOR UNIDIRECTIONAL GRAPHITE/POLYIMIDE COMPOSITE 12-PLY LAMINATES. EACH DATA POINT IS THE AVERAGE FOR TEN BEND-SHEAR TEST SPECIMENS AND $f$ I IS FIBER FRACTION. THE ESIIMATOR IS DEFINED IN TERMS OF AN EQUATION THAT COMBINES STRESS WAVE FACIOR, E $E_{C}$. AND SURFACE-PARALLEL VELOCITY, $V_{S}$, MEASUREMEÑTS [18]. 


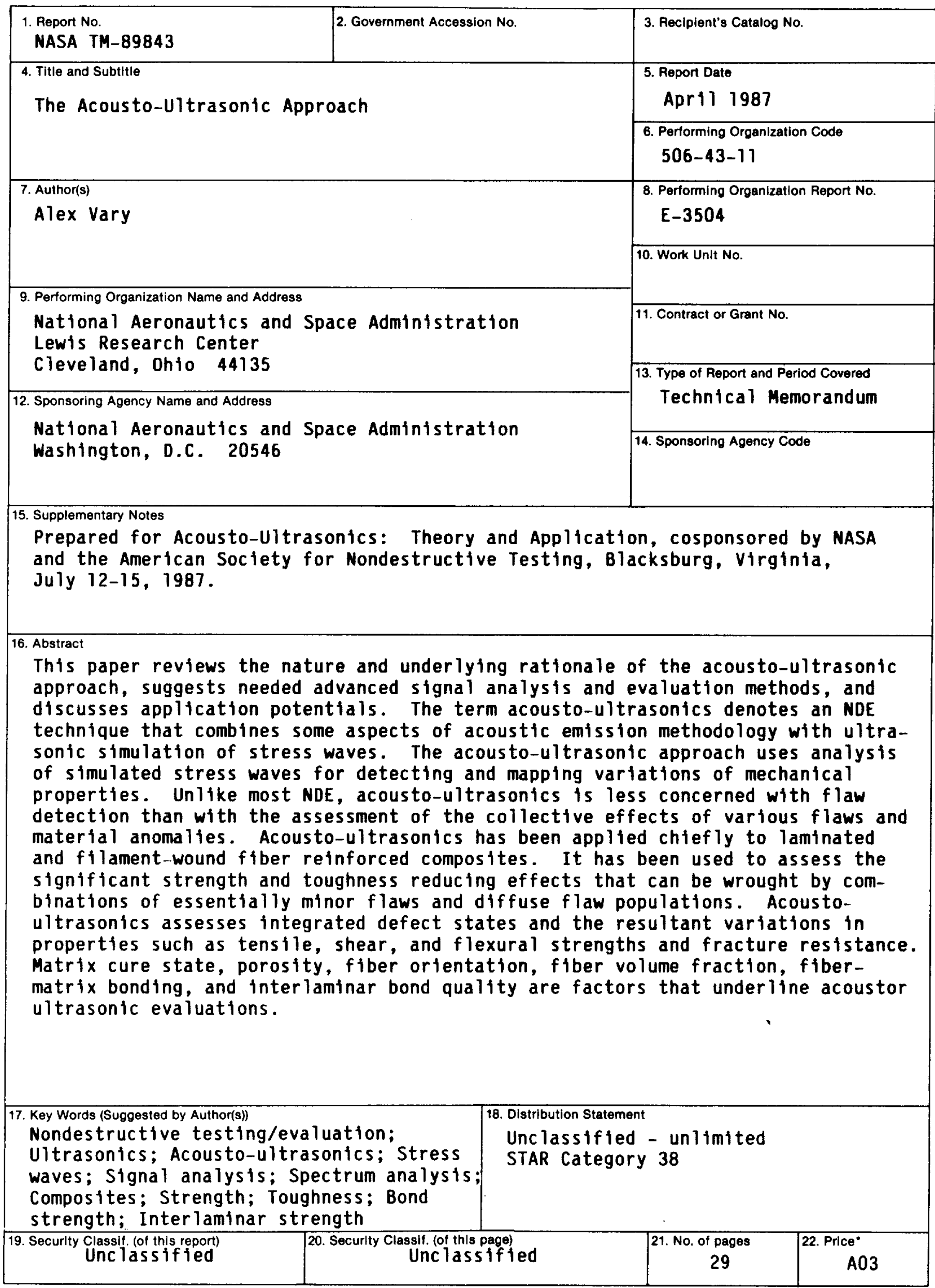

"For sale by the National Technical Information Service, Springfield, Virginia 22161 
